\title{
DUAS NOVAS ESPÉCIES DE ASTEROCHERIDAE (COPEPODA: SIPHONOSTOMATOIDA) ASSOCIADAS A ESPONJAS NA BAÍA DE TODOS-OS-SANTOS, BAHIA, BRASIL
}

\author{
Borges, C.C. ${ }^{1,}{ }^{*}$; Neves, E. ${ }^{1}$ \& Johnsson, R. ${ }^{1}$ \\ ${ }^{1}$ Universidade Federal da Bahia (UFBA), Campus Ondina, \\ Laboratório de invertebrados marinhos: Crustacea, cnidaria e fauna associada (LABIMAR). \\ *Autor correspondente: camilacborges.bio@gmail.com
}

\begin{abstract}
Asterocheridae é uma grande família de copépodes sifonostomatóides que vive associada à invertebrados marinhos e algas, conta atualmente com 56 gêneros conhecidos, sendo Asterocheres Boeck, 1860 o seu gênero tipo. Estudos recentes restringiram a diagnose de Asterocheres, hoje precipuamente baseada no padrão de fusão dos artículos antenulares e em seis caracteres estritos da armadura de suas pernas natatórias. Seguindo essa proposta o gênero conta atualmente com 63 espécies descritas e vive associado principalmente a organismos dos filos Porifera, Cnidaria e Equinodermata, sendo o primeiro seu hospedeiro preferencial. Estudos realizados na praia da Boa Viagem, na Baía de Todos-os-Santos, revelaram duas novas espécies do gênero Asterocheres associadas as esponjas Callyspongia sp. Duchassaing \& Michelotti, 1864 e Aplysina fistularis (Pallas, 1766). Ambas espécies apresentam variações, sobretudo em suas antenas e peças bucais, que combinadas, resultam em diferenças consideráveis em relação aos seus congêneres. Os Asterocheres podem apresentar entre 19 e 21 artículos em sua antênula e por conta disso subdividem-se em três grandes grupos, sendo o maior deles formado pelos que apresentam 21 artículos. A sp. nov. 1 possui 20 artículos na antênula e a sp. nov. 2 possui 21, assim como outros 19 e 33 congêneres respectivamente. Refinando ainda mais as comparações, a sp. nov. 1 apresenta palpo mandibular 1-segmentado e maxilípede 6-segmentado assim como outros 3 congêneres e a sp. nov. 2 palpo 2-segmentado e maxilípede também com 6 segmentos, em comum com outros 6 congêneres e ainda assim ambas revelam uma combinação única de caracteres. Este é o primeiro registro de associação de Asterocheres a Aplysina fistularis e pela terceira vez a área estudada evidencia o seu enorme potencial para a existência de novas espécies de copépodes simbiontes. A praia da Boa Viagem já apresenta dois registros de copépodes sifonostomatóides (Asterocheres siphunculus Bahia et al. 2012 e Spongiopsyllus redactus Canário et al. 2012) e com o presente trabalho passará a ter quatro registros, reforçando a necessidade de mais estudos na localidade a fim de ampliar a nossa compreensão sobre a fauna de copépodes simbiontes que ela abriga.
\end{abstract}

Palavras-chave: taxonomia, fauna associada, copépodes simbiontes, Eucidaris tribuloides, Amphiroa sp. 